\title{
Life with a Gastric Band. Long-Term Outcomes of Laparoscopic Adjustable Gastric Banding-a Retrospective Study
}

\author{
Piotr K. Kowalewski ${ }^{1}$ - Robert Olszewski ${ }^{2}$ - Andrzej Kwiatkowski ${ }^{1}$ • \\ Natalia Galązka-Świderek $^{3}$ • Krzysztof Cichoń ${ }^{3} \cdot$ Krzysztof Paśnik $^{1}$ \\ Published online: 27 October 2016 \\ (C) The Author(s) 2016. This article is published with open access at Springerlink.com
}

\begin{abstract}
Background Laparoscopic adjustable gastric banding (LAGB) is the third most popular bariatric procedure worldwide. Various authors present ambivalent long-term follow up results.

Methods We revised records of the patients who underwent LAGB between 2003 and 2006 along with history of additional check-ins. Patients with outdated details were tracked with the national health insurance database and social media (Facebook). An online survey was sent. The patients who did not have their band removed were included in this study. We calculated the percent total weight loss (\%TWL) and percent excess weight loss (\%EWL), along with changes in body mass index $(\triangle \mathrm{BMI})$. Satisfactory weight loss was set at $>50 \%$ EWL (for BMI $=25 \mathrm{~kg} / \mathrm{m}^{2}$ ). Since eight patients gained weight, we decided to include negative values of $\% \mathrm{TWL}$, $\%$ EWL, and $\triangle \mathrm{BMI}$.

Results One hundred seven patients underwent LAGB from 2003 to 2006. The mean follow-up time was $11.2( \pm 1.2)$ years. Eleven percent of patients were lost to follow up $(n=12)$. There was one perioperative death. Fifty-four of the patients $(n=57)$ had their band removed. Thirty-seven patients still have the band $(39 \%)$ and were included in the study. The mean \%EWL was $27 \%(-56-112 \%)$ and \%TWL was $11 \%$ $(-19-53 \%)$. Twelve patients achieved \%EWL > 50\% (32\%).
\end{abstract}

Piotr K. Kowalewski

pietia.kowalewski@gmail.com

1 Department of General Surgery, Military Institute of Medicine, Szaserów 128, 04-141 Warsaw, Poland

2 Department of Cardiology, Military Institute of Medicine, Warsaw, Poland

3 Department of Internal Medicine, Regional Hospital, Łęczna, Poland
Thiry-two patients still suffer from obesity, with BMI over $30 \mathrm{~kg} / \mathrm{m}^{2}$. Eight patients (22\%) gained additional weight. Patients with \%EWL $>50 \%$ suffered less from gastroesophageal reflux disease symptoms than those with $\mathrm{EWL}<50 \%$ $(p<0.05)$.

Conclusions Out of 107 cases, only $11.2 \%$ of patients with gastric band $(n=12)$ achieved satisfactory \%EWL. Twentytwo percent of patients regained their weight or even exceeded it. Overall results suggest that LAGB is not an effective bariatric procedure in long term observation.

Keywords Laparoscopy · Bariatric surgery · LAGB · Gastric band · Long term follow-up

\section{Introduction}

Adjustable gastric banding was first introduced as a bariatric procedure in the mid-80s [1]. Its overall simplicity, and the development of laparoscopy allowed surgeons to implement a minimally invasive technique, which, by this day is known as laparoscopic adjustable gastric banding (LAGB) [2]. It is the third most popular bariatric surgery, representing $10 \%$ of all the procedures in 2013 [3]. Interestingly, in 2008 LAGB was the most commonly performed procedure for patients suffering from obesity, with $42.3 \%$ of all bariatric surgeries [4]. Bearing in mind this decrease, still over 40,000 patients undergo this operation worldwide every year, according to the 2013 survey. The overall change in popularity may be attributed to doubts regarding its effectiveness in the long-term research [5]. Yet, a number of large, prospective studies acknowledge LAGB as a successful bariatric procedure [6]. In our study, we would like to focus on the long-term history of patients who underwent LAGB and still live with a gastric band. 


\section{Aim}

To evaluate long-term clinical outcomes of laparoscopic adjustable gastric banding (LAGB) regarding weight loss, physical activity and complaints of gastroesophageal reflux disease (GERD) in patients are living with the gastric band.

\section{Materials and Methods}

Our institution database was revised for the record of patients who underwent LAGB between 2003 and 2006. We have gathered the data on their weight, body mass index (BMI), and co-morbidities. The history of additional check-ins was revised. The patients who did not fulfill their check-ins and whose personal data was outdated were tracked using the national health insurance database, or found using social media (Facebook and LinkedIn) and its support groups. These patients received and filled out an online questionnaire regarding their current weight, medical history, complaints of GERD, physical activity habits-expressed by regular, over 30-min exercise routine, and sedentary behavior, assessed by hours spent siting down on a daily basis. The patients who did not have their band removed were included in this study. To measure the effectiveness of the procedure, the percentage total weight loss (\%TWL), percentage excess weight loss (\%EWL), and change in body mass index $(\triangle \mathrm{BMI})$ were calculated.

We calculated the excess weight (EW) from the weight before surgery subtracted by ideal body weight (IBW) for BMI of $25 \mathrm{~kg} / \mathrm{m}^{2}$. Satisfactory weight loss after the surgery was defined by the EWL greater than 50\%.

We performed the statistical analysis using "Statistica" software (StatSoft). Normality of the data was tested with Shapiro-Wilk test. Continuous variables were compared with the student $t$ test. Categorical variables were compared using the $\mathrm{chi}^{2}$ test. Statistical significance was set at $p<0.05$.

Since eight patients gained weight, we decided to include negative values of $\% \mathrm{TWL}, \% \mathrm{EWL}$, and $\triangle \mathrm{BMI}$.

\section{Results}

One hundred seven patients underwent LAGB between 2003 and 2006 in our institution. There was one perioperative death $(0.09 \%)$. Eleven percent of patients were lost to follow up $(\boldsymbol{n}=12)$. Fifty-four percent of patients ( $n=57$ ) had their band removed. Out of the remaining group, $39 \%$ of patients $(n=37)$ still live with a functioning gastric band and were included in this study. The mean follow-up time was $11.2( \pm 1.2)$ years. There were $78 \%$ female $(n=29)$ and $22 \%$ male $(n=8)$
Table 1 Demographic data

\begin{tabular}{lll}
\hline & Value & Percent (SD) [range] \\
\hline Gender (female/male) & $29 / 8$ & $78 \% / 22 \%$ \\
Age & 37 & {$[20-63]$} \\
Mean weight $(\mathrm{kg})$ & 120.7 & $( \pm 17.0)[90-150]$ \\
Mean BMI $\left(\mathrm{kg} / \mathrm{m}^{2}\right)$ & 42.3 & $( \pm 4.3)[33.7-52.1]$ \\
Mean excess weight $(\mathrm{kg})$ & 49.3 & $( \pm 12.7)[24.4-76.0]$ \\
\hline
\end{tabular}

patients. The mean patients' age was 37 years (ranging from 20 to 63) and mean BMI before the surgery was $42.3( \pm 4.3)$ (Table 1). Several complications led to the band removal. The main causes were the following: weight gain $(40 \%)$, pouch slippage $(25 \%)$, port complications, such as infection and dislocation $(21 \%)$, pouch dilatation (16\%), and band erosion (5\%) (Table 2). The long-term outcomes of LAGB in the study group are presented in Table 3 and Fig. 1. The mean excess weight loss was $27 \%(-56-112 \%)$ and total weight loss was $11 \%(-19 \%-53 \%)$. Thirty-two percent of patients achieved \%EWL > 50\% $(n=12) .86 \%$ of patients $(n=32)$ still suffer from obesity, with BMI over $30 \mathrm{~kg} / \mathrm{m}^{2}$. It should be noted that eight patients gained additional weight $(22 \%)$, exceeding their body mass from before the surgery. Interestingly, mean maximum $\%$ EWL recorded in the follow-up reached $69 \%$. Over half $(57 \%)$ of the patients achieved it in the first year after the surgery.

Regarding physical activity and habits, 15 patients $(41 \%)$ exercised regularly for at least $30 \mathrm{~min}$ daily. Mean sedentary time in all patients was $7 \mathrm{~h}$ per day. Therefore, the patients were divided into two groups according to the achieved $\%$ EWL over and under $50 \%$, physical activity, and gained weight. These groups were then compared regarding different parameters. There was a statistically significant difference in GERD symptoms reported between patients with $\% \mathrm{EWL}>50 \%$ (group 1) and \%EWL $<50 \%$ (group 2). Only $5(42 \%)$ patients from group 1 suffered from GERD, compared to $19(79 \%)$ from group $2(p<0.05)$. Other differences were not statistically significant (Table 4 ).

Table 2 Causes of revisional surgery after LAGB

\begin{tabular}{lcc}
\hline Causes & Number & Percent \\
\hline Weight gain & 23 & 40 \\
Slippage & 14 & 25 \\
Pouch dilatation and reflux & 9 & 16 \\
Band erosion & 3 & 5 \\
Port problem (infection, dislocation) & 12 & 21 \\
\hline
\end{tabular}


Table 3 Long term outcomes of LAGB

\begin{tabular}{lll}
\hline & Value & Percent (SD) [range] \\
\hline Time of follow-up (years) & 11.2 & $( \pm 1.1)$ \\
$\%$ EWL & $27 \%$ & $( \pm 38 \%)[-56-112 \%]$ \\
$\% \mathrm{TWL}$ & $11 \%$ & $( \pm 15 \%)[-19-53 \%]$ \\
$\Delta \mathrm{BMI}$ & 4.71 & $( \pm 6.65)[-7.3-25.3]$ \\
Number of patients with \%EWL $>50 \%$ & 12 & $33 \%$ \\
Number of patients with weight gain & 8 & $22 \%$ \\
\hline
\end{tabular}

\section{Discussion}

According to WHO, obesity affected 600 million people worldwide in 2014. Thirteen percent of the world population was suffering from obesity. These numbers doubled since 1980. Over the years, new methods of treatment became available to patients. Current research supports bariatric surgery as the most effective one. [7, 8]. Out of all the variety of existing procedures, LAGB is the third most popular in the world, according to the survey from 2013. Ten percent of the bariatric patients, almost 40,000 people worldwide, undergo this procedure every year [3]. In Poland, LAGB is preceded by laparoscopic sleeve gastrectomy (LSG), laparoscopic Roux-en-Y gastric bypass (LRYGB), and mini gastric bypass (MGB). Adjustable band accounts for $7.6 \%$ of bariatric procedures [9]. There are several qualities that make LAGB such a popular procedure. It is fairly uncomplicated in the hands of an experienced surgeon. It has good short-term effects, and is mostly reversible. Even in our study, $69 \%$ of the patients achieved satisfying \%EWL over $50 \%$ at some point after the surgery. Yet when it comes to long-term results, the outcomes are not as favorable. Although O'Brien et al. report a stunning $47 \%$ excess weight loss in a 15 -year follow-up, yet over $50 \%$ of patients had their band removed, with or without additional bariatric surgery, such as LRYGB or LSG [6]. Other authors

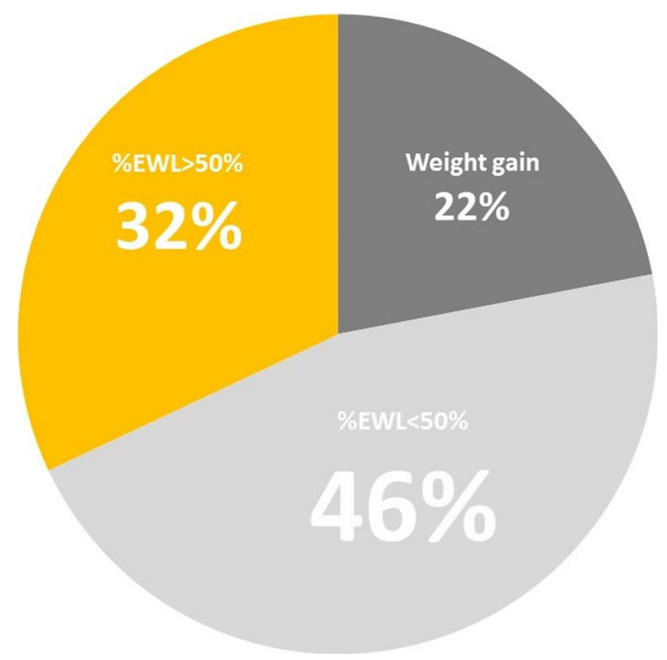

Fig. 1 Long term outcomes of LAGB
Table 4 Difference between patients with $\% \mathrm{EWL}>50 \%$ and $\%$ EWL $<50 \%$

\begin{tabular}{llll}
\hline & $\begin{array}{l}\text { Group 1 } \\
(\text { EWL }>50 \%)\end{array}$ & $\begin{array}{l}\text { Group 2 } \\
(\text { EWL }<50 \%) \\
n=25\end{array}$ & $p$ value \\
\hline $\begin{array}{c}\text { GERD } \\
\text { symptoms }\end{array}$ & $5(42 \%)$ & $20(80 \%)$ & $<0.05^{\mathrm{a}}$ \\
$\begin{array}{c}\text { Sedentary } \\
\text { hours (mean) } \\
\begin{array}{c}\text { Physically } \\
\text { active }\end{array}\end{array}$ & $5.8( \pm 3)$ & $7.6( \pm 2.6)$ & $p=0.069^{\mathrm{b}}$ \\
\hline${ }^{\mathrm{a}}$ Chi ${ }^{2}$ test & $9(50 \%)$ & $p=0.41^{\mathrm{a}}$ \\
${ }^{\mathrm{b}} t$ student test & & & \\
\end{tabular}

do not present such favorable long-term outcomes of LAGB. Aarts et al. report that only $22 \%$ of all LAGB patients maintain a functioning band with good results. Fifty-three percent of the patients underwent a revisional procedure and/or band removal [10]. Sutter et al. underlines linear progression of major complications and even states in the conclusion that LAGB should not be considered a procedure of choice for treating obesity [5]. Himpens et al. also reaches the conclusion that LAGB long term effects are poor due to a high reoperation rate [11]. When it comes to co-morbidities, its reduction in short-term follow-up is not maintained in the long term [10]. Out of many studied co-morbidities, only glucose tolerance improves and maintains its improvement in long term observation [12]. GERD and its symptoms are also frequently mentioned regarding bariatric surgery. Naik et al. state that adjustable gastric banding worsens GERD or even forms de novo cases in previously asymptomatic patients [13]. Greater amount of GERD and dysphagia symptoms in patients with $\%$ EWL lower than $50 \%$ in our study may suggest dietary inaccuracy in this particular group. Overall, bariatric surgery tends to improve patients' physical activity [14]. Yet, in our observation, only $41 \%$ of patients remain physically active, with average daily sedentary time as long as $7 \mathrm{~h}$.

\section{Conclusions}

Only $39 \%$ of patients still maintain a functioning band after over 10 years. The rest of the patients had their band removed due to various complications. Out of all of the patients, only $11.2 \%$ of them achieved satisfactory $\%$ EWL over $50 \%$, which means that the band fail rate reached $88.8 \%$. Twenty-two percent of patients from the study group regained their weight or even exceeded it. Over half of the patients suffer from dysphagia, more often when weight loss is not satisfactory, which suggests that these patients do not comply to dietary guidelines. Overall results suggest that LAGB is not an effective bariatric procedure in long term observation. 


\section{Compliance with Ethical Standards}

Conflict of Interest The authors declare that they have no conflict of interest.

Ethical Statement All procedures performed in studies involving human participants were in accordance with the ethical standards of the institutional and/or national research committee and with the 1964 Helsinki declaration and its later amendments or comparable ethical standards.

Consent Statement Informed consent was obtained from all individual participants included in the study.

Open Access This article is distributed under the terms of the Creative Commons Attribution 4.0 International License (http:// creativecommons.org/licenses/by/4.0/), which permits unrestricted use, distribution, and reproduction in any medium, provided you give appropriate credit to the original author(s) and the source, provide a link to the Creative Commons license, and indicate if changes were made.

\section{References}

1. Kuzmak L. Silicone gastric banding: a simple and effective operation for morbid obesity. Contemp. Surg. 1986; 28.

2. Cadière GB, Bruyns J, Himpens J, et al. Laparoscopic gastroplasty for morbid obesity. Br J Surg. 1994;81:1524.

3. Angrisani L, Santonicola A, Iovino P, et al. Bariatric surgery worldwide 2013. Obes Surg. 2015;25:1822-32.
4. Buchwald H, Oien DM. Metabolic/bariatric surgery worldwide 2008. Obes Surg Springer Science + Business Media. 2009;19: $1605-11$.

5. Suter M, Calmes JM, Paroz A, et al. A 10-year experience with laparoscopic gastric banding for morbid obesity: high long-term complication and failure rates. Obes Surg. 2006;16:829-35.

6. O'Brien PE, MacDonald L, Anderson M, et al. Long-term outcomes after bariatric surgery: fifteen-year follow-up of adjustable gastric banding and a systematic review of the bariatric surgical literature. Ann Surg. 2013;257:87-94.

7. Gloy VL, Briel M, Bhatt DL, et al. Bariatric surgery versus nonsurgical treatment for obesity: a systematic review and metaanalysis of randomised controlled trials. BMJ. 2013;347:f5934.

8. Colquitt JL, Pickett K, Loveman E, et al. Surgery for weight loss in adults. Cochrane Database Syst Rev. 2014;8:CD003641.

9. Janik MR, Stanowski E, Paśnik K. Present status of bariatric surgery in Poland. Videosurgery Miniinv. 2016;1:22-5.

10. Aarts EO, Dogan K, Koehestanie P, et al. Long-term results after laparoscopic adjustable gastric banding: a mean fourteen year follow-up study. Surg Obes Relat Dis. 2014;10:633-40.

11. Himpens J, Cadière G-B, Bazi M, et al. Long-term outcomes of laparoscopic adjustable gastric banding. Arch Surg American Medical Association. 2011;146:802-7.

12. Zakaria AS, Rossetti L, Cristina M, et al. Effects of gastric banding on glucose tolerance, cardiovascular and renal function, and diabetic complications: a 13-year study of the morbidly obese. Surg Obes Relat Dis. 12:587-95.

13. Naik RD, Choksi YA, Vaezi MF. Impact of weight loss surgery on esophageal physiology. Gastroenterol Hepatol (N Y). 2015;11:801-9.

14. King WC, Chen J-Y, Belle SH, et al. Change in pain and physical function following bariatric surgery for severe obesity. JAMA. 2016;315:1362-71. 